\title{
AVALIAÇÃO DO ESPAÇO AÉREO FARÍNGEO PELA TOPOGRAFIA COMPUTADORIZADA HELICOIDAL
}

\section{EVALUATION OF THE PHARINGEAL AIRSPACE USING HELICAL COMPUTED TOPOGRAPHY}

\author{
David Peters dos Santos* \\ Wagner Fernandes de Oliveira" \\ Maria José APS Tucunduva*
}

\section{RESUMO}

\begin{abstract}
A faringe é um conduto musculomembranoso responsável pela condução dos alimentos, dos líquidos e do ar. Sua anatomia é bastante complexa devido a suas conexões ósseas, musculares e mucosas. Diversos fatores podem contribuir para a interrupção das vias aéreas superiores. A síndrome da apneia do sono é uma desordem respiratória que ocorre quando as paredes do espaço aéreo faríngeo entram em colapso. A diminuição do tamanho do espaço nasofaríngeo resulta em um desequilíbrio funcional com impacto no crescimento e desenvolvimento craniofacial. Para compreender a fisiologia e patogênese da obstrução das vias aéreas superiores (VAS) é essencial o conhecimento da morfologia e do funcionamento das estruturas esqueléticas e do tecido mole. Diversos métodos são utilizados no estudo da obstrução das VAS. A imagem do espaço aéreo superior mostra informações adicionais a respeito da anatomia do fluxo aéreo. Essas informações são úteis para direcionar o tipo de tratamento a ser realizado.
\end{abstract}

Descritores: Faringe $\bullet$ Tomografia computadorizada por Raios $X \bullet$ Síndromes da apneia do sono $\bullet$ Apneia.

\section{ABSTRACT}

The pharynx is a muscled-membranous tube responsible for the conduction of food, liquids and air. Its anatomy is quite complex due to its bone, muscle and mucous connections. Several factors may contribute to a disruption of the upper airways. The syndrome of sleep apnea is a respiratory disorder that occurs when the walls of the pharyngeal airway space collapse. When there is a size reduction of the nasopharyngeal space, the result is a functional imbalance with an impact on both craniofacial growth and development. To a better understanding of the physiology and pathogenesis of upper airway obstruction, it is essential a good knowledge of both morphology and function of skeletal structures and soft tissue. Several methods are used to study the airway obstruction. The image of the upper airspace shows additional information about the airflow anatomy. This information is useful to direct the type of treatment to be performed.

Descriptors: Pharynx $\bullet$ Tomography $\bullet$ X-ray computed $\bullet$ Sleep apnea syndromes $\bullet$ Apnea 
SANTOS DP

OLIVEIRA WF TUCUNDUVA MJAPS

AVALIAÇÃO DO

ESPAÇO AÉREO

FARÍNGEO PELA

TOPOGRAFIA

COMPUTADORIZADA

HELICOIDAL

14

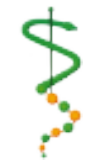

REV. ODONTOL.

UNIV. CID, SÃO

PAULO

$2014 ; 26(1): 12$

22, JAN-ABR

\section{N T RO DUÇÃO}

A faringe é um conduto musculomembranáceo, posicionado verticalmente, situado diante da coluna cervical, atrás das fossas nasais, boca e laringe, abaixo da porção basilar do osso occipital e entre os dois ramos da mandíbula, coberta em sua parte interna pelos músculos pterigóideos laterais direito e esquerdo ${ }^{1}$.

A faringe é uma via comum para condução dos alimentos, dos líquidos e do ar que contém oxigênio. $\mathrm{O}$ ar provindo da boca e cavidade nasal passa pela faringe e flui ao longo da laringe para dentro da traqueia ${ }^{2}$.

O tubo digestório e a via aérea entrecruzam-se em forma de $X$, pois o conduto esofágico encontra-se localizado atrás do conduto laringotraqueal. Ocupando a região do crânio e do pescoço, a primeira porção da faringe é ocultada lateralmente pelo ramo vertical da mandíbula e para seu acesso é necessária ampla extração cirúrgica deste ramo. A segunda porção é muito mais acessível, na qual o osso hioide é o único osso de pequenas dimensões que impede o acesso pela via anterior ${ }^{1}$.

Devido a essas conexões ósseas e também a suas conexões musculares e mucosas, a faringe, para os anatomistas, não possui uma individualidade topográfica isolável e bem definida. É constituída de uma encruzilhada aerodigestória, que está condicionalmente construída conforme sua dupla função, por isso, sua anatomia é bastante complexa. Anteriormente se comunica com a cavidade nasal pelos coanos, com as fauces pelo ístimo e com a laringe pelo ádito'.

Na região contínua ao esôfago, a faringe é revestida por epitélio pavimentoso estratificado não queratinizado com função principal de proteção e secreção e, nas regiões próximas à cavidade oral, é revestida por epitélio pseudoestratificado cilíndrico ciliado que tem a função de proteção, secreção e transporte de partículas aderidas ao muco mediadas pelos cílios ${ }^{3}$.

O muco secretado parcialmente por células caliciformes individuais e por pequenas glândulas submucosas formam uma camada que mantém úmidas todas as vias respiratórias do nariz até os bronquíolos terminais. O revestimento epitelial ciliado mantém seus movimentos ciliares sempre na direção da faringe, para que o muco e suas partículas capturadas sejam engolidos ou expelidos pelo reflexo da tosse $\mathrm{e}^{4}$.

A faringe possui tonsilas que são constituídas por aglomerados de tecido linfoide incompletamente encapsulado e estão em contato com o epitélio. As tonsilas estão estrategicamente posicionadas nas porções iniciais do tubo digestório para defender o organismo contra antígenos transportados pelo ar e também pelos alimentos, iniciando uma resposta imunitária ${ }^{3}$.

A tonsila faríngea situa-se na porção superoposterior da faringe, recoberta por epitélio pseudoestratificado cilíndrico ciliado contendo algumas áreas com epitélio estratificado plano. As tonsilas linguais são menores e mais numerosas, encontram-se na base da língua recobertas por epitélio estratificado pavimentoso. As tonsilas palatinas localizam-se na região da fauce, cada uma possui invaginações epiteliais que penetram no parênquima formando criptas. As criptas possuem células epiteliais descamadas (linfócitos vivos e mortos e bactérias) que podem aparecer como pontos purulentos nas tonsilites (amidalites), ou seja, inflamação e eventual infecção das tonsilas ${ }^{3}$.

As complicações da tonsilite aguda normalmente possuem origem bacteriana e podem incluir abscessos peritonsilares e parafaríngeos e linfoadenite cervical supurativa, entre outras complicações ${ }^{5}$.

Alterações no tamanho do espaço aéreo posterior e desordens respiratórias do sono podem ser produzidas pelo crescimento da base anterior do crânio e do complexo maxilomandibular. Geralmente essas alterações ocorrem quando as paredes do espaço aéreo entram em colapso, ocasionando a síndrome da apneia e hipopneia obstrutiva do sono (SAHOS) representando o estágio mais severo ${ }^{6}$.

Normalmente durante a inspiração, é observado um reflexo, caracterizado pelo aumento da atividade dos músculos dilatadores da faringe, minimizando o estreitamento da mesma, por conta da pressão intraluminal negativa. O músculo genioglosso é o mais estudado, pois ele é muito importante para a dilatação da faringe. Durante a respiração, sua atividade fási- 
ca encontra-se diminuída nos pacientes com SAHOS e poderá gerar deslocamento posterior da língua durante o sono, contribuindo para a oclusão das vias aéreas superiores (VAS) ${ }^{7}$.

Durante o sono, os músculos ficam hipotônicos e a estabilidade do espaço aéreo torna-se dependente do tamanho da faringe $e^{6}$.

Nos adultos, a apneia é definida como a interrupção do fluxo aéreo por mais de dez segundos, a hipopneia é definida como a redução de mais de $50 \%$ do fluxo respiratório por período acima de dez segundos e ambas apresentam cinco ou mais eventos respiratórios por hora de sono ${ }^{7}$.

Em alguns pacientes, pode ocorrer sonolência excessiva devido à fragmentação do sono que ocorre nos despertares no final de um episódio de apneia ${ }^{8}$.

São registrados durante o procedimento da polissonografia os movimentos corporais, estágios e continuidade do sono, esforço respiratório, saturação de oxigênio, posição do corpo e eletrocardiograma ${ }^{9}$.

As crianças com distúrbios respiratórios durante o sono podem apresentar ronco primário, apneia central, obstrutiva ou mista e a hipopneia. A incidência maior é observada nas fases pré-escolares. Nessa faixa etária é mais comum a obstrução das vias aéreas superiores devido à hipertrofia das tonsilas palatinas ou da tonsila faríngea. A apneia central ocorre quando o comando do sistema nervoso central interrompe a musculatura respiratória, cessando o fluxo aéreo oronasal juntamente com os movimentos torácicos e abdominais. Na apneia obstrutiva, ocorre a interrupção do fluxo aéreo oronasal devido ao colabamento das vias aéreas superiores (VAS). A apneia mista está relacionada tanto à diminuição do comando respiratório central quanto à obstrução das VAS. Hipopneia é caracterizada pela redução parcial do fluxo aéreo oronasal. O ronco primário é identificado pelo quadro clínico, caracterizado pelo ruído respiratório, mantendo-se normal a arquitetura do sono, a ventilação alveolar e a saturação de oxigênio da hemoglobina ${ }^{10}$.

O mecanismo de colapso das VAS nos homens e nas mulheres é anatomicamente diferente. No homem, apresenta-se maior o ângulo entre o palato duro e o palato mole, chegando em torno de 47,1 graus; já nas mulheres, esse ângulo fica em torno de 43,3 graus ${ }^{7}$.

Conforme a pressão faríngea torna-se cada vez mais negativa, a língua e a úvula colocam-se contra a parede posterior da faringe. Entretanto, a cada valor negativo, o colapso das VAS nas mulheres torna-se menor do que nos homens ${ }^{7}$.

Dos pacientes com apneia, aproximadamente $58 \%$ podem apresentar micrognatismo mandibular (tamanho diminuído da mandibula) ou retrognatismo mandibular (posicionamento posterior da mandíbula em relação à maxila). É importante destacar a posição do osso hioide; normalmente nos indivíduos saudáveis ele está situado ao nível da vértebra cervical C3-C4, enquanto que nos pacientes com SAOS o osso hioide encontra-se situado ao nível de C4-C67.

Para compreender a fisiologia e patogênese da obstrução do espaço aéreo faríngeo superior é essencial o conhecimento da morfologia e o funcionamento das estruturas esqueléticas e do tecido mole. No entanto, sua avaliação é complexa, pois sua localização não permite uma visualização direta ${ }^{11}$.

Diversos métodos são utilizados no estudo da obstrução das VAS, incluindo-se exame físico, nasofaringolaringoscopia, cefalometria, tomografia computadorizada e ressonância magnética ${ }^{12}$.

Cada método possui vantagens e desvantagens que são inevitáveis, sem um consenso quanto ao procedimento padrão -ouro ${ }^{11}$.

A imagem do espaço aéreo faríngeo superior mostra informações adicionais a respeito da anatomia do fluxo aéreo. A cefalometria e o exame radiográfico podem determinar os fatores anatômicos contribuintes para a síndrome. Essas informações são úteis para direcionar o tratamento cirúrgico. A cefalometria radiográfica está sendo utilizada como ferramenta de estudo na mensuração do espaço aéreo faríngeo e na morfologia craniofacial, oferecendo vantagens como baixo custo, baixa exposição a radiação e permitindo simultaneamente análise da posição da
SANTOS DP

OLIVEIRA WF

TUCUNDUVA MJAPS

AVALIAÇÃO DO

ESPAÇO AÉREO

FARÍNGEO PELA

TOPOGRAFIA

COMPUTADORIZADA

HELICOIDAL
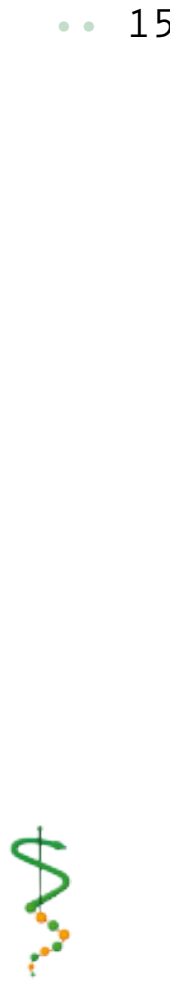

REV, ODONTOL.

Univ. CId. São

paulo

2014; 26(1): 12 -

22 , JAN-ABR 
SANTOS DP

OLIVEIRA WF TUCUNDUVA MJAPS

AVALIAÇÃO DO

ESPAÇO AÉREO

FARÍNGEO PELA

TOPOGRAFIA

COMPUTADORIZADA

HELICOIDAL

$16 \ldots$

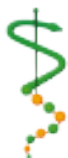

REV, ODONTOL.

UNIV, C I D . SÃO

PAULO

$2014 ; 26(1): 12-$

22 , JAN-ABR cabeça, do osso hioide e também da morfologia craniofacial, mas apresenta pouco referencial de partes moles ${ }^{6}$.

Na faringe, os principais parâmetros a serem medidos estão na distância entre a parede posterior da faringe e a base da língua ou palato mole, ou seja, região do espaço aéreo faríngeo posterior. Essa região possui três diferentes níveis: espaço aéreo posterior superior ou velofaríngeo que está situado entre a parede posterior da faringe e o contorno posterior do palato mole (ao nível do plano palatino); espaço aéreo posterior médio que está situado entre a parede posterior da faringe e o limite inferior da úvula palatina; e espaço aéreo posterior inferior que está situado entre a parede posterior da faringe e a base da língua (ao nível da linha mandibular) ${ }^{7}$.

A radiografia cefalométrica proporciona inúmeras informações, porém, esbarra na capacidade de fornecer somente imagem bidimensional de uma estrutura tridimensional, não possibilitando uma avaliação precisa da complexidade dessa estrutura e de suas dimensões ${ }^{11}$.

Com a tomografia computadorizada de feixe cônico (TCFC) tornou-se possível adquirir imagens de todas as estruturas do complexo maxilofacial em volume. Através de softwares específicos juntamente com protocolos de aquisição baseados nas necessidades individuais, podemos transformar esse volume digital em imagens multiplanares (axiais, coronais e sagitais). O software possui ferramentas que permitem realizar mensurações relativas às estruturas ósseas e também realizar avaliações dos tecidos moles em 3D. Os tomógrafos computadorizados de feixe cônico estão se tornando cada vez mais eficientes, através da redução de tempo da aquisição da imagem e do desenvolvimento de softwares específicos, permitindo melhor processamento e análise da imagem tridimensional da região maxilofacial. Utilizando ferramentas específicas a imagem pode ser melhor observada, podendo ser girada ou aumentada, para permitir melhor avaliação das regiões de interesse, sendo renderizadas em qualquer ângulo, escala ou posição. Podem ser aplicados diferentes tipos de filtros, permitindo a análise entre tecidos de den- sidades diferentes. Proporciona também a ferramenta de transparência, permitindo a visualização do tecido duro através do tecido mole. Por meio da medição linear, podem ser avaliadas a altura, a largura e a profundidade de qualquer parte da faringe. As imagens podem ser transformadas em arquivos DICOM (Digital Imaging and Communications in Medicine), possibilitando a exportação da imagem para outros softwares de avaliação tridimensional, possibilitando assim maior gama de recursos na avaliação do espaço aéreo ${ }^{11}$.

$\mathrm{O}$ tratamento pode ser tanto conservador como cirúrgico. O tratamento conservador utiliza máscaras de pressão positiva contínua de ar (Continuous Positive Air Pressure - CPAP) ou aparelhos intrabucais, com o objetivo de avançar a mandíbula e mantê-la em uma relação oclusal de protrusão durante o sono ${ }^{13}$.

O Herbst ${ }^{\circledR}$ é um aparelho com mecanismo telescópico bilateral, ancorado nos arcos superior e inferior. Mesmo durante todas as funções mandibulares, o Herbst ${ }^{\circledR}$ mantém a mandíbula em posição postural anterior contínua ${ }^{14}$.

Aidar et al. ${ }^{14}$ (2009) descreveram que a terapia com Herbst ${ }^{\circledR}$ resulta em redirecionamento do crescimento da maxila, movimento mesial dos dentes inferiores e movimento distal dos dentes superiores.

A cirurgia ortognática tem sido uma excelente opção de tratamento para os pacientes que possuem estreitamento da cavidade nasofaríngea resultante das anormalidades anatômicas maxilomandibulares. O tratamento ortognático envolve tanto o avanço da maxila e da mandíbula quanto o do mento, podendo ser realizado com a combinação dos três procedimentos, porém, o mais comum é o avanço da maxila e mandíbula, com ou sem genioplastia ${ }^{6}$.

\section{OB JET I V 0}

Este trabalho tem como objetivo, estabelecer as dimensões do espaço aéreo faríngeo por meio da tomografia computadorizada helicoidal.

\section{METODOLOG I A}

O estudo foi realizado na forma de uma análise exploratória de uma amos- 
tra de conveniência de 89 exames de tomografia computadorizada helicoidal, pertencentes a um banco de dados de pacientes com solicitação de exame da face; o projeto foi aprovado no CEP (15299713.8.0000.0064). As imagens foram analisadas em cortes axiais, nos quais o espaço aéreo faríngeo foi mensurado tanto no sentido anteroposterior quanto laterolateralmente. Foram critérios de exclusão pacientes que foram submetidos a cirurgia prévia.

A amostra foi constituída por 37 homens e 52 mulheres com média de 36,8 anos de idade cronológica. A mensuração

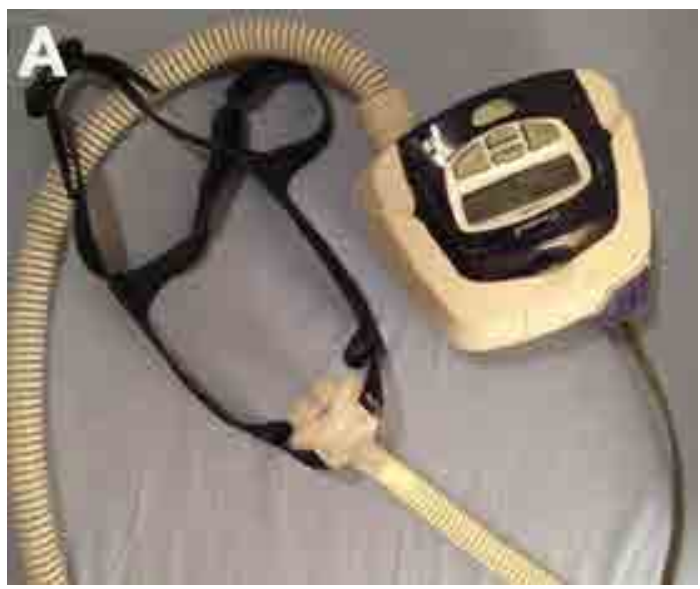

foi feita por meio do programa ImageJ $\mathbb{R}$ (Fiji and Related Software). Para a análise estatística o software utilizado foi o Prisma® no teste de U Mann Whitney.

\section{RESULTADOS}

Por meio dos exames analisados, 9\% apresentaram média abaixo de $2 \mathrm{~cm}$ de largura e $15 \%$ apresentaram média abaixo de $1,2 \mathrm{~cm}$ de profundidade. Na maioria das imagens analisadas, a profundidade apresentou dimensão menor do que a largura, $2 \%$ apresentaram profundidade com valores menores que $0,5 \mathrm{~cm}$ e $1 \%$ apresentou a maior mensuração chegando a

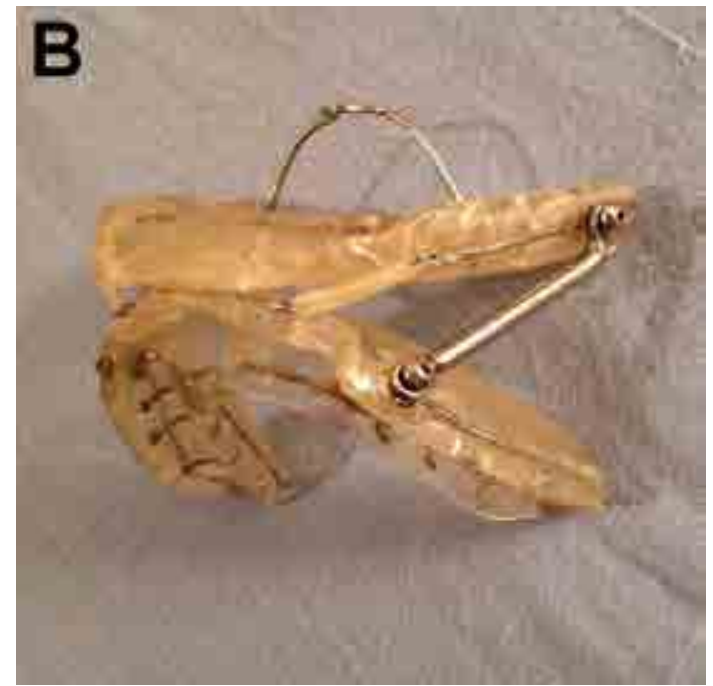

SANTOS DP

OLIVEIRA WF

TUCUNDUVA MJAPS

AVALIAÇÃO DO

ESPAÇO AÉREO

FARÍNGEO PELA

TOPOGRAFIA

COMPUTADORIZADA

HELICOIDAL

Figura 1 - Aparelhos ultilizados no tratamento para correção da mandibula.

A) CPAP é uma máscara de pressão positiva contínua de ar; B) Herbst é um aparelho com mecanismo telescópico bilateral.
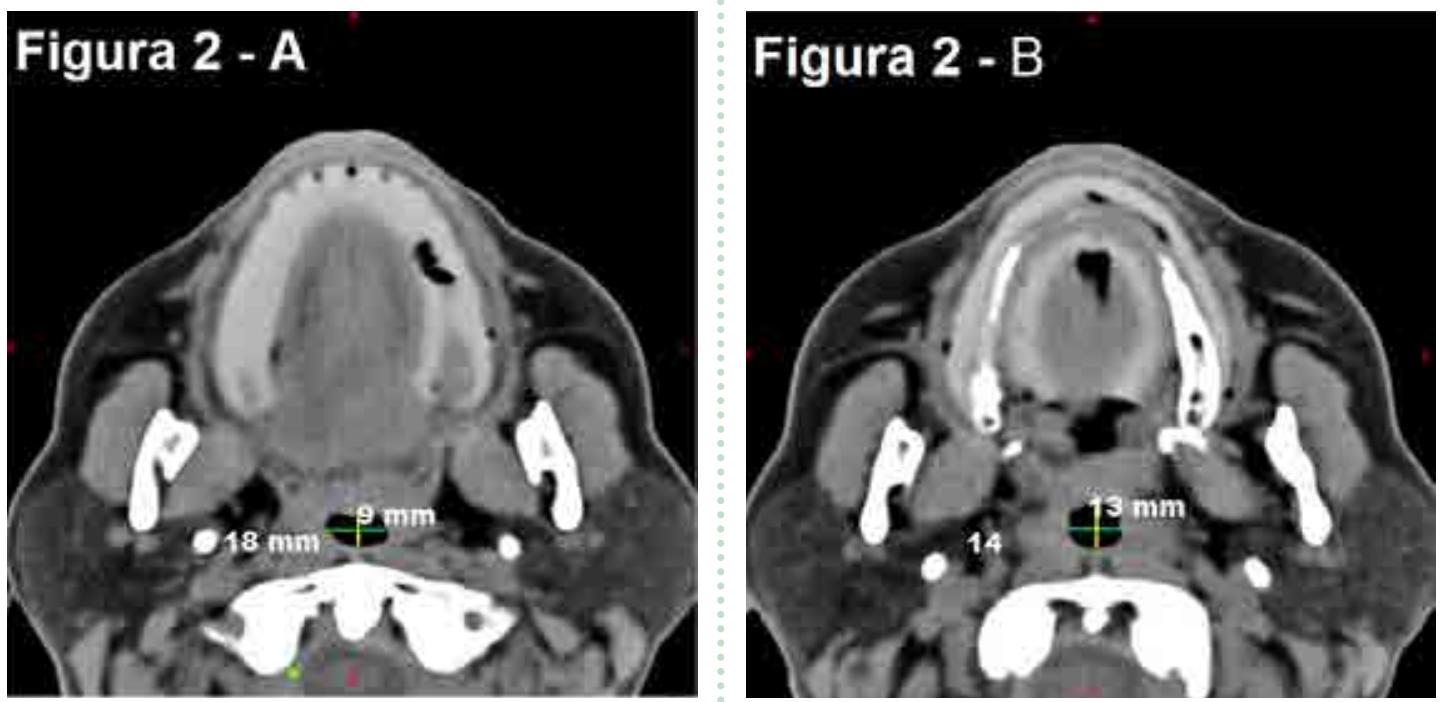

Figura 2 - A e B: TC em corte axial, do gênero feminino, 60 anos de idade cronológica. Dimensão do espaço aéreo faríngeo. Largura Profundidade

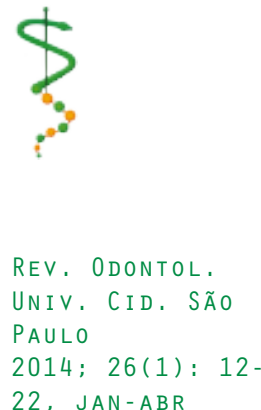


SANTOS DP

OLIVEIRA WF

TUCUNDUVA MJAPS

AVALIAÇÃO DO

ESPAÇO AÉREO

FARINNGEO PELA

TOPOGRAFIA

COMPUTADORIZADA

HELICOIDAL
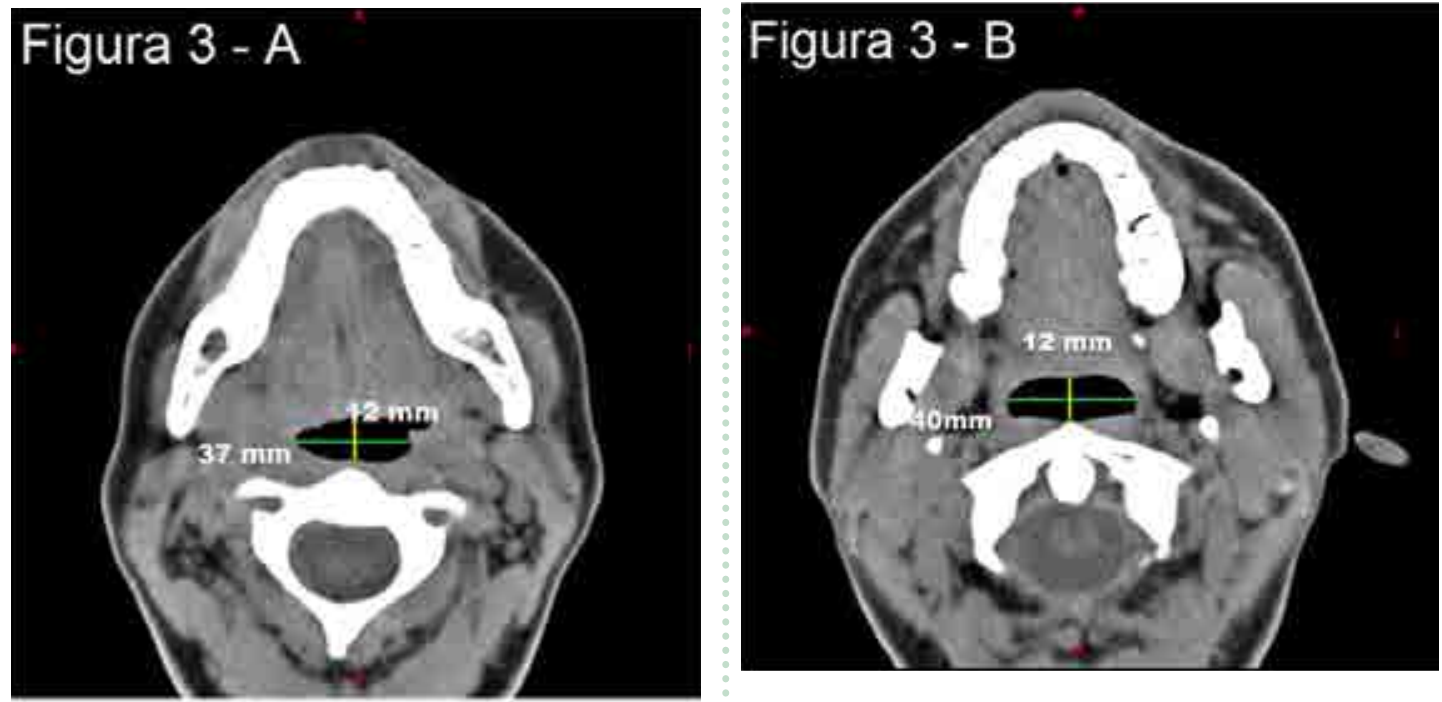

Figura 3 - A e B: TC em corte axial, do gênero masculino, 32 anos de idade cronológica. Dimensão do espaço aéreo faríngeo. — Largura Profundidade
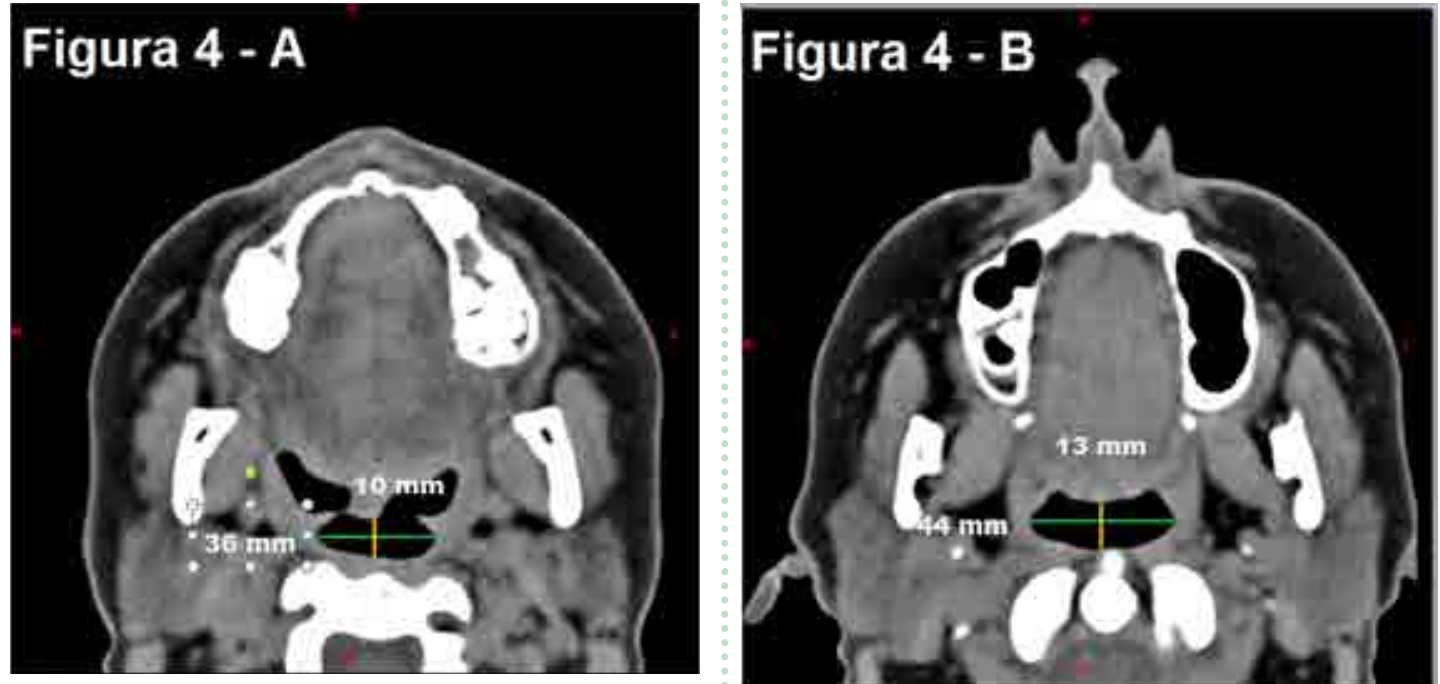

Figura 4 - A e B: TC em corte axial, do gênero feminino, 39 anos de idade cronológica. Dimensão do espaço aéreo faríngeo — Largura Profundidade
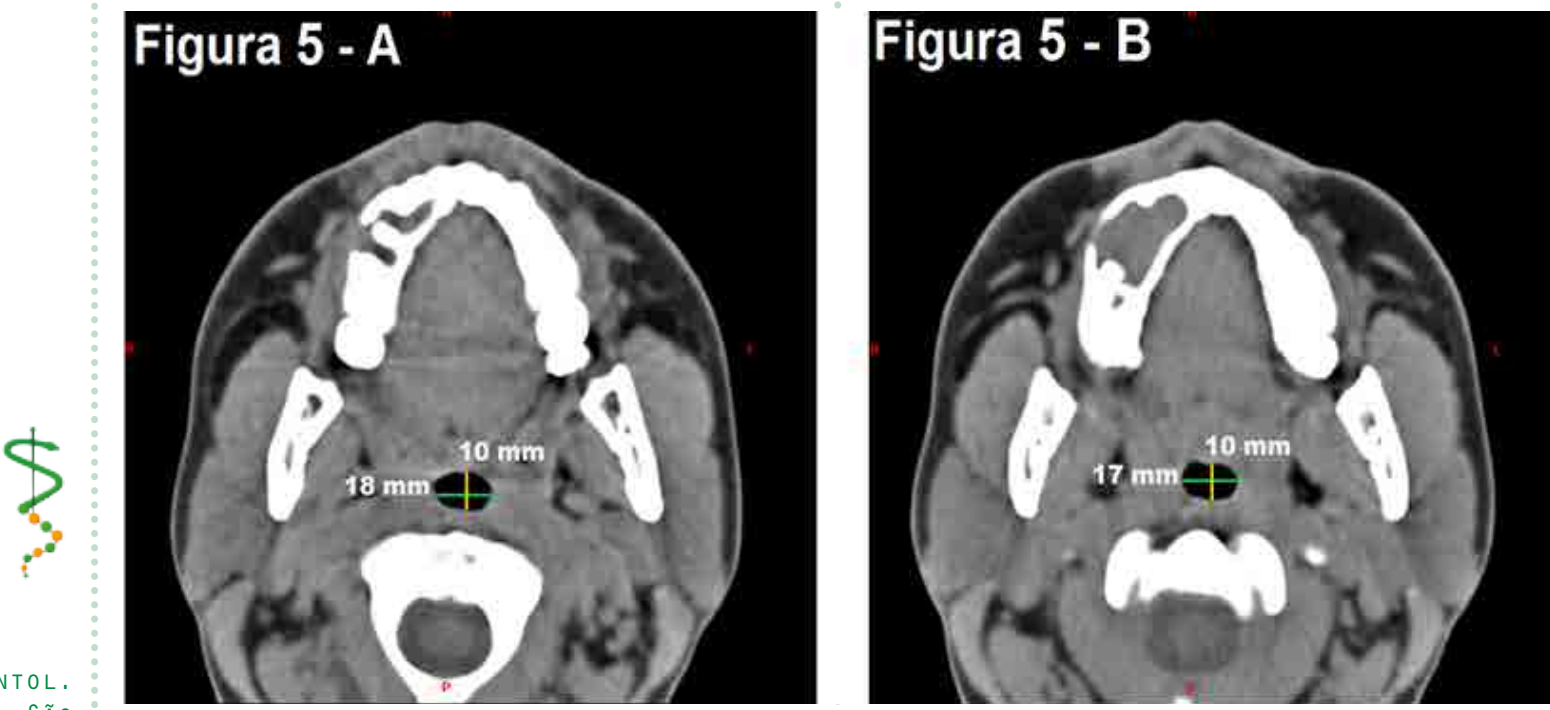

UNIV, CID, SÃO

PAULO

$2014 ; 26(1): 12$

22, JAN-ABR
Figura 5 - A e B: TC em corte axial, do gênero feminino, 29 anos de idade cronológica. Dimensão do espaço aéreo faríngeo ¿ Largura Profundidade 

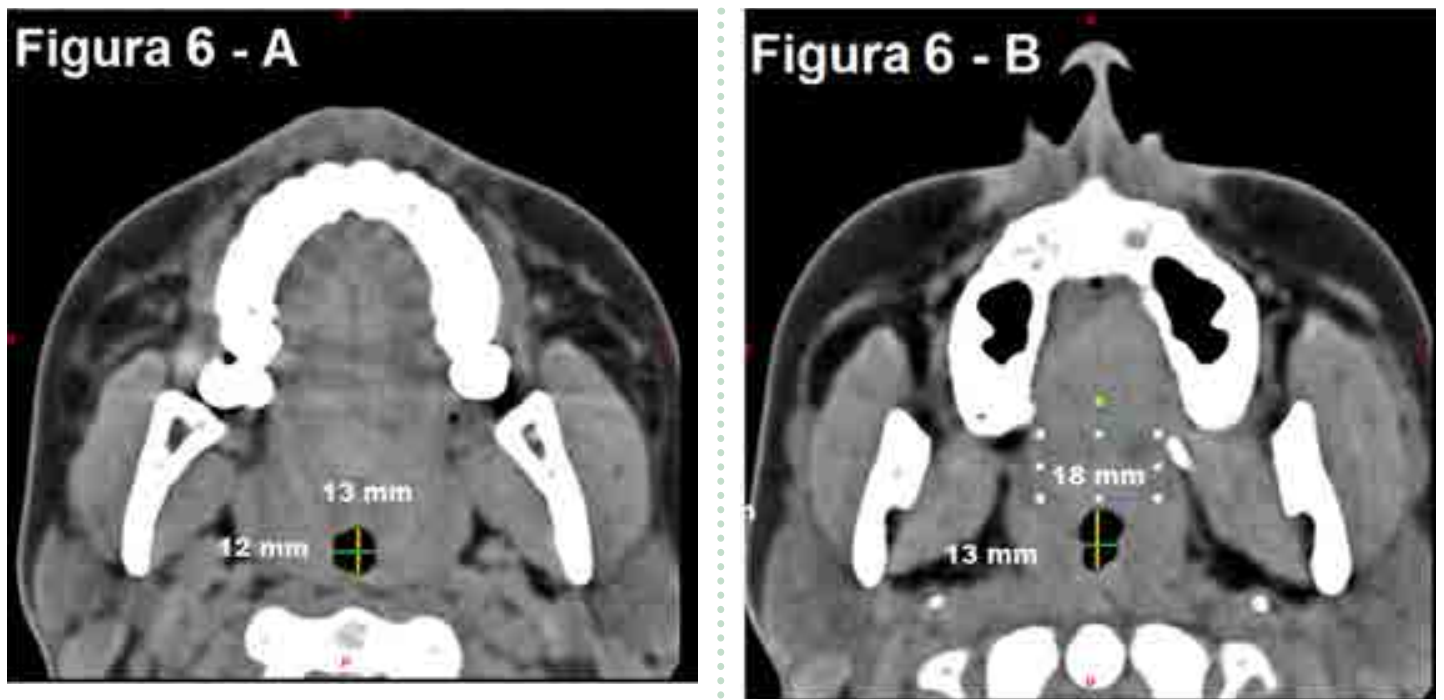

SANTOS DP

OLIVEIRA WF

TUCUNDUVA MJAPS

AVALIAÇÃO DO

ESPAÇO AÉREO

FARÍNGEO PELA

TOPOGRAFIA

COMPUTADORIZADA

HELICOIDAL

Figura 6 - A e B: Figura 6 - A e B: TC em corte axial, do gênero masculino, 20 anos de idade cronológica. Dimensão do espaço aéreo faríngeo.

- Largura Profundidade

\section{6,3cm de largura.}

Nas figuras, observamos os exames de tomografia computadorizada helicoidal. Estabelecemos a dimensão da faringe em largura e profundidade, identificadas respectivamente nas cores verde e amarelo. Em relação à altura, a própria aquisição da imagem, em cortes axiais, nos fornece alturas diferentes no que se refere à estrutura de interesse.

Em relação às figuras $4 \mathrm{~A}$ e $\mathrm{B}$ e figuras $5 \mathrm{~A}$ e $\mathrm{B}$, observamos nitidamente a diferença entre os tamanhos da faringe, que na Figura 5 A e B se apresenta mais estreita, principalmente em relação à largura; além disso, podemos observar também que as duas figuras são do gênero feminino e com pouca diferença de idade cronológica, nos mostrando que a idade não

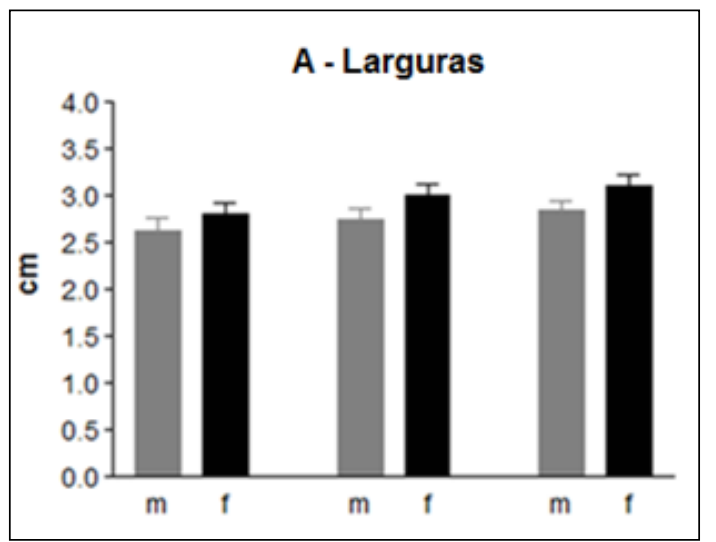

Gráfico 1 - a) O gênero feminino possui tendência para a largura ser maior comparado ao gênero masculino; b) Observamos o gênero masculino com tendência a ter a profundidade maior.

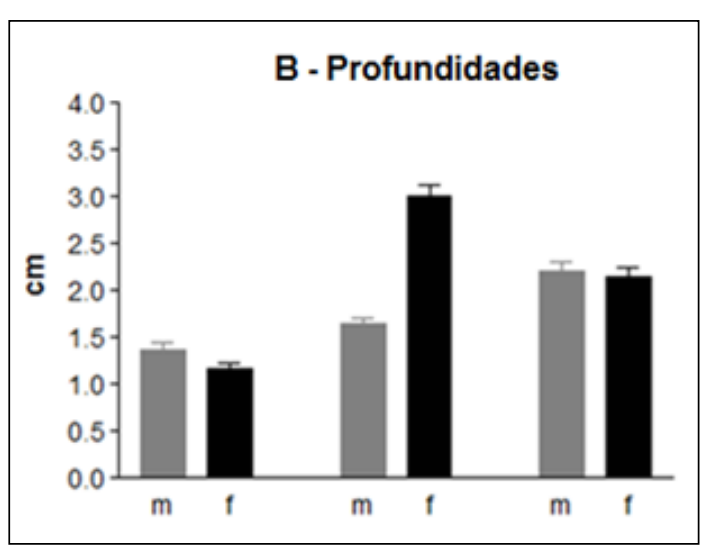

influencia na dimensão da faringe.

Com base nos dados da análise estatística realizada, podemos observar nos gráficos 1 e 2 a média dos resultados dos 89 exames mensurados, em relação à largura e à profundidade, comparando-se as três imagens de cada paciente do gênero masculino e feminino.

Nos gráficos 3 e 4 observamos a média dos resultados em largura comparando a idade dos pacientes. Comparamos o gênero masculino com o feminino com idade de 0 até 30 anos no Gráfico 3 e depois comparamos a faixa etária de 31 anos em diante no Gráfico 4.

Nos gráficos 5 e 6 observamos a média dos resultados em profundidade comparando a idade dos pacientes. Comparamos o gênero masculino com feminino

REV. ODONTOL.

UNIV, C I D , SÃO PAULO

2014; 26(1): 12 -

22 , JAN-ABR 
SANTOS DP

OLIVEIRA WF TUCUNDUVA MJAPS

AVALIAÇÃO DO

ESPAÇO AÉREO

FARÍNGEO PELA

TOPOGRAFIA

COMPUTADORIZADA

HELICOIDAL
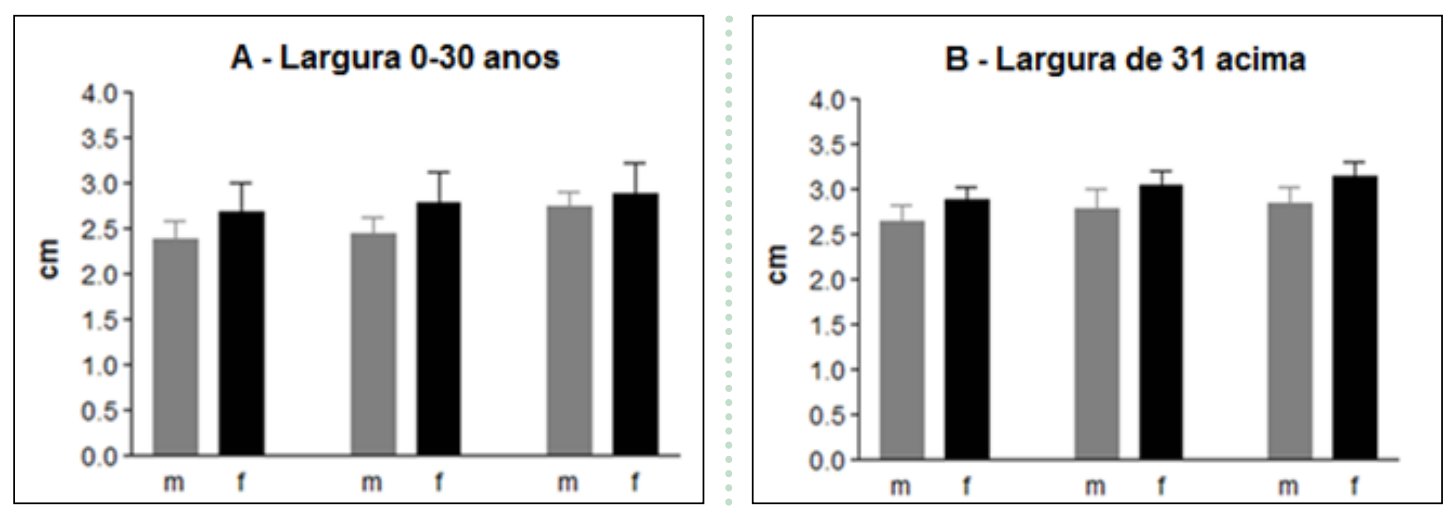

Gráfico 2 - a) Comparação da largura, entre os gêneros masculino e feminino, com idade de $O$ até 30 anos; b) Comparação da largura, entre os gêneros masculino e feminino, com idade acima de 31 anos.

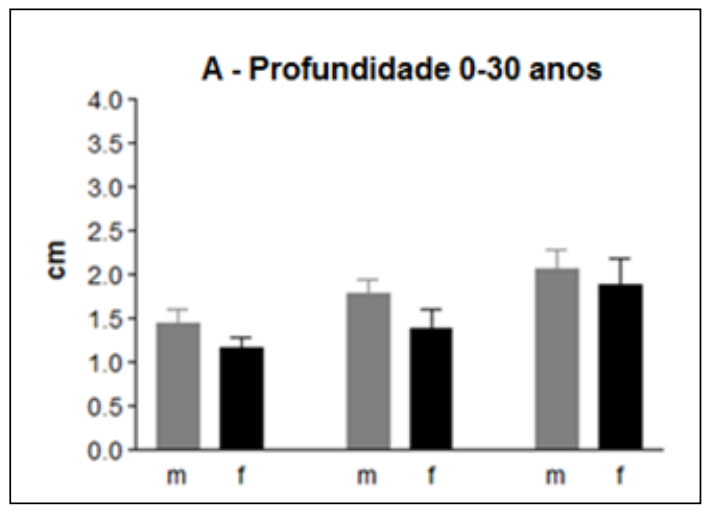

com idade de 0 até 30 anos no gráfico 5 e depois comparamos a faixa etária de 31 anos em diante no Gráfico 6.

\section{I SCUSSÃO}

Para realização das mensurações do espaço aéreo faríngeo utilizamos 89 exames de tomografia computadorizada, e foram selecionadas 3 imagens em cortes axiais de cada paciente, utilizando o mesmo padrão anatômico para todos. Logo depois, cada imagem foi mensurada no sentido anteroposterior (profundidade) e laterolateralmente (largura) através do programa ImageJ®.

Esse programa fornece uma ferramenta que nos permite realizar a mensuração de uma estrutura em milímetros. As mensurações foram realizadas com sucesso, nas quais obtivemos a dimensão do espaço aéreo faríngeo, estabelecendo sua largura e profundidade. Essas informações podem ser importantes e eficazes para auxiliar o médico no diagnóstico da síndrome da apneia e hipopneia do sono.

Para Pereira Filho et al. ${ }^{6}$ (2007), durante o sono os músculos estão hipotônicos

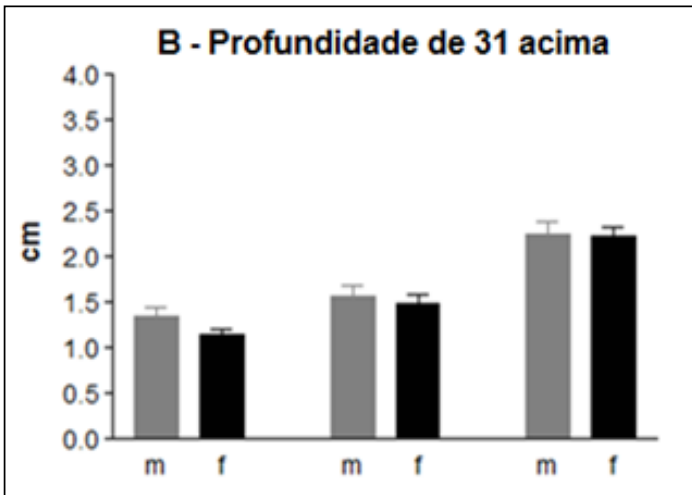

e a estabilidade do espaço aéreo torna-se dependente do tamanho da faringe. Com relação a isso, percebemos durante a análise dos exames de tomografia computadorizada que houve diferença no tamanho da faringe entre os pacientes, pois alguns obtiveram a dimensão diminuída em relação aos outros, e podem sofrer influência na estabilidade do espaço aéreo durante o sono.

Para Salles et al. ${ }^{7}$ (2005), o ângulo entre o palato duro e palato mole no homem encontra-se maior do que na mulher e essa diferença anatômica influencia no mecanismo de colapso das VAS. Nas mensurações realizadas durante este trabalho não obtivemos diferença significativamente relevante entre homens e mulheres, Observamos que no gênero feminino ocorreu uma tendência a ter a largura em tamanho maior comparado ao gênero masculino e, em relação à profundidade, o gênero masculino tende a ser maior, porém não avaliamos o ângulo entre o palato duro e o palato mole, então não avaliamos se essas tendências estão relacionadas ao ângulo das estruturas palatinas. 
Em relação aos métodos diagnósticos, para Pereira Filho et al. ${ }^{6}$ (2007) a cefalometria radiográfica oferece vantagens em relação com outras técnicas, devido a seu baixo custo para realização do exame e exposição mínima à radiação, mas apresenta pouco referencial de partes moles. Na tomografia computadorizada a vantagem está na obtenção de três diferentes tipos de cortes (axial, sagital e coronal) para aquisição das imagens, além disso, possui ferramentas de reconstrução 3D, possibilitando uma avaliação mais precisa de uma estrutura, porém esbarra em um exame de alto custo e maior exposição à radiação.

Zinsly et al. ${ }^{11}$ (2010) descrevem que, para compreensão da fisiologia e patogênese da obstrução do espaço aéreo faríngeo superior, é essencial ter o conhecimento da morfologia e o funcionamento das estruturas esqueléticas e do tecido mole, sua avaliação é complexa, pois sua localização não permite uma visualização direta. Podemos observar nas imagens de tomografia computadorizada que temos informações importantes em relação ao posicionamento das estruturas esqueléticas e do tecido mole, além disso, conseguimos analisar diretamente o espaço aéreo faríngeo evitando as sobreposições que poderiam interferir no diagnóstico.

Com relação à faixa etária dos pacientes, observamos que não houve diferença significativa na dimensão da faringe, não ocorreu predominância entre as idades em possuir uma dimensão maior ou menor. Comparamos as idades cronológicas de 0 até 30 anos e de 31 anos acima.

\section{CONCLUSÃO}

Por meio do estudo realizado foi possível concluir que:

1 - Houve a possibilidade de estabelecer as dimensões em profundidade e largura do espaço aéreo faríngeo.

2 - Observamos que no gênero feminino ocorreu uma tendência a ter a largura em maior tamanho, comparado ao gênero masculino.

3 - Em relação à profundidade, o gênero masculino tende a ser maior.
SANTOS DP

OLIVEIRA WF

TUCUNDUVA MJAPS

AVALIAÇÃO DO

ESPAÇO AÉREO

FARÍNGEO PELA

TOPOGRAFIA

COMPUTADORIZADA

HELICOIDAL

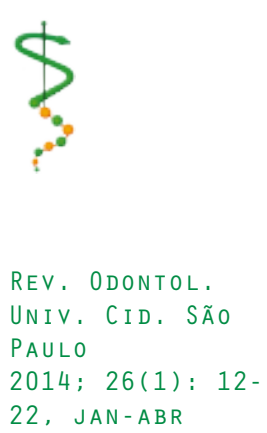


SANTOS DP

OLIVEIRA WF TUCUNDUVA MJAPS

AVALIAÇÃO DO

ESPAÇO AÉREO

FARÍNGEO PELA

TOPOGRAFIA

COMPUTADORIZADA

HELICOIDAL

REV, ODONTOL

UNIV. CID. SÃO

PAULO

$2014 ; 26(1): 12-$

22, JAN-ABR

\section{REFERÊNCIAS}

1. Testut L, Latarjet A. Tratado de anatomia humana. 2. ed. Barcelona: Salvat; 1978.

2. Silverthorn D. Fisiologia humana: uma abordagem integrada. 2. ed. Barueri, SP: Manole; 2003.

3. Junqueira LC. Histologia básica. 11. ed. Rio de Janeiro: Guanabara Koogan; 2008.

4. Guyton A. Tratado de fisiologia médica. 11. ed. Rio de Janeiro: Guanabara Koogan; 2006.

5. Cecatto SB, Garcia RID, Costa KS, Novais RAB, Yoshimura R, Rapoport PB. Síndrome de Guillain-Barré como complicação de amigdalite aguda. Rev Bras Otorrinolaringol 2003 ago;69(4):566-9.

6. Pereira Filho VA, Jeremias F, Tedeschi L, Souza RF. Avaliação cefalométrica do espaço aéreo posterior em pacientes com oclusão Classe II submetidos à cirurgia ortognática. Rev Dent Press Ortodon Ortop Facial, Maringá 2007 out;12(5):119-25.

7. Salles C, Campos PSF, Andrade NA, Daltro C. Síndrome da apnéia e hipopnéia obstrutiva do sono: análise cefalométrica. Rev Bras Otorrinolaringol 2005 jun;71(3):369-72.

8. Musman S, Passos VMA, Silva IBR, Barreto SM. Avaliação de um modelo de predição para apneia do sono em pacientes submetidos a polissonografia. J bras pneumol 2011 fev.;37(1):7584.
9. Gondim LMA, Matumoto LM, Melo Júnior MAC, Bittencourt S, Ribeiro UJ. Estudo comparativo da história clínica e da polissonografia na síndrome da apnéia/ hipopnéia obstrutiva do sono. Rev Bras Otorrinolaringol 2007 dez;73(6):733-7.

10. Balbani APS, Weber SAT, Montovani JC, Carvalho LR. Pediatras e os distúrbios respiratórios do sono na criança. Rev Assoc Med Bras 2005 abr;51(2):80-6.

11. Zinsly SR, Moraes LC, Moura P, Ursi W. Avaliação do espaço aéreo faríngeo por meio da tomografia computadorizada de feixe cônico. Dental Press J Orthod 2010 out;15(5):150-8.

12. Faria AC, Garcia LV, Santos AC, Diniz PR, Ribeiro HT, Mello-Filho FV. Comparison of the area of the pharynx during wakefulness and induced sleep in patients with obstructive sleep apnea (OSA). Braz J Otorhinolaryngol 2012 Feb;78(1):103-8.

13. Gonçales ES. Estudo cefalométrico computadorizado do espaço aéreo faríngeo de pacientes submetidos à cirurgia ortognática para correção de prognatismo mandibular [Tese]. Bauru: Faculdade de Odontologia de Bauru; 2006.

14. Aidar LAA, Dominguez GC, Gonzalez PLSA, Mantovani MGD. Tratamento ortopédico com aparelho de Herbst: ocorrem mudanças verticais no padrão de crescimento facial? Rev Dent Press Ortodon Ortop Facial 2009 dez;14(6):72-81. 